\title{
A personal financial planning system for everyday use?
}

\author{
S. D. Gregor
}

Faculty of Business, Central Queensland University

Rockhampton Queensland Australia 4702

Telephone: (079) 309682 Facsimile: (079) 309700

Email: s.gregor@cqu.edu.au

\begin{abstract}
Systems for financial planning exist. Many of these systems are, however, complex, expensive and designed for use by specialists. In the project described in this paper the aim was to investigate whether a knowledge-based system could be developed for "everyday" use by people engaged in financial planning. A system was developed, entitled the Retirement and Pension system (RAP), to deal with investment planning for people who could be eligible for an Age Pension. The system deals with simplified situations and generic investments. Trials with 91 members of the general public indicated that the system was regarded favourably and could be used successfully in problem solving. Investigation of problem solving behaviour with the system showed different patterns of behaviour - a considerable amount of "what-if" analysis, and some use of the explanation facility and help functions.
\end{abstract}

\section{Keywords}

Knowledge-based systems, financial planning, problem solving, explanations.

\section{INTRODUCTION}

The motivation to engage in the current research arose from personal experience with people of retirement age engaged in investment planning. These people had little prior experience with financial planning and had difficulty in fully understanding the courses of action suggested to them by financial planners in consultations limited by time constraints. Investigation of the outcomes of investment strategies privately was difficult because of the complexities of the income tax and social security legislation, as well as the mathematics involved in calculating the yield from investments. These problems have practical significance. Service products such as superannuation are of major importance to the Australian economy and difficulty in understanding such products can have adverse effects on their use (Ward, 1995). 
The aims of the research were: (i) to develop a knowledge-based system (KBS) that could be used by "ordinary" people to investigate and learn about investment planning for retirement, and (ii) to investigate the problem solving strategies employed by users of the system.

Prior successes with KBS indicated that the development of such a system was feasible. KBS for financial planning include PlanPower, from Applied Expert Systems (Stansfield and Greenfield, 1987) and the Personal Financial Planning system developed by Coopers and Lybrand (Wiig, 1988). These systems, however, are large, expensive, and required considerable effort to develop. Some KBS are available "off-the-shelf" - for example, a personal income tax system, AskDAN (Legal Knowledge Systems, 1988; Miastkowski, 1988). A number of KBS which are based on government legislation have been successfully implemented (Gregor, 1991; Gregor, Rigney and Smith, 1991; Gregor and Watts, 1991; Johnson and Mead, 1991). Previous experiences indicate that KBS can aid learning (Eining and Dorr, 1991; Fedorowicz, Oz, and Berger, 1992; Gregor, 1991; Gregor et al, 1991). Professional financial planners, however, when consulted about building the system described here, expressed doubts as to whether a system that was suitable for use by the general public could be developed.

The system developed was named RAP - the "Retirement And Pension" system. Data concerning the system was gathered during trials with members of the general public. The research is primarily descriptive and relies on analysis of written responses from the participants and the automatically recorded traces of their activities while using the system.

The problem solving behaviour of people using the KBS was expected to be congruent with a cognitive effort perspective or cost-benefit principle (Payne, Bettman and Johnson, 1993). This view is based on numerous empirical studies (Beach and Mitchell, 1978; Payne, 1976; Payne, Bettman and Johnson, 1993; Todd and Benbasat, 1991). The cognitive effort perspective proposes that strategy selection in decision making is a compromise between a desire to make a correct decision and the desire to minimise effort. The least effortful strategy will be followed, subject to an acceptable solution being found.

A measure used to evaluate cognitive effort is the number of elementary information processes (EIPs) required to perform a task, a measure first introduced by Newell and Simon (1972). EIPs include as primitives the process of discrimination (choice), comparison, storing and reading a symbol. Thus, an explanation involving a large number of reading and storing operations would require more cognitive effort than a "what-if" process, where a user changed the value of one variable and observed the result.

Results of trials with 91 people indicated that they found the system was useful and easyto-use. Preliminary analysis of problem solving behaviour with the system is congruent with the cognitive effort perspective - a considerable amount of "what-if" analysis being observed.

\section{DESIGN AND DEVELOPMENT OF THE RAP SYSTEM}

The RAP system was developed with assistance from four professional financial planners. Two were associated with major banks, one with a private financial planning firm, and one with the Department of Social Security. The program was written in the VisualBasic for Windows language (Microsoft, 1993).

The system is designed for cases where a person has some funds available for investment and is possibly eligible for the Department of Social Security age pension. The user enters personal details, such as amount available for investment and current income, and preferences 
as to income requirements, income versus capital growth, cash requirements, and risk tolerance. The program then allocates the amount available for investment among different generic investment types, taking the user's preferences such as risk tolerance into account. The heuristic rules for the investment allocation were developed by synthesising the practices described by each of the financial planners, with some help from written sources. After investments are allocated, income and growth projections and tax and pension calculations are performed. The process is iterative in some cases where an annuity is required to bring an income stream to a certain level. The final solution is displayed on a screen with details of the individual investments, projected income and growth figures, annual gross income, Department of Social Security pension if any, tax payable, and net income. Users can then access an explanation facility to see the guidelines used in allocating the investments and the details of tax and pension calculations. The program has some features not found in programs currently used by the financial planners, though overall it is far less complex and deals with a subset of possible situations.

\section{EXPERIMENTAL STUDY}

The system was tested in laboratory sessions. One hundred and thirty people responded to requests for participation in the study. Analysis was based on a sample of 91 participants: 52 males and 39 females. Table 1 gives descriptive statistics for the sample analysed.

The study described here was part of a larger project which included an investigation into the effects of the availability of an explanation facility in KBS (Gregor, 1996). Thus, two forms of the KBS were used, one with an explanation facility and one without. The materials used in the study included an information sheet, a consent form, a step-by-step guide to the system with familiarisation activities, a set of problems (either collaborative or non-collaborative), and evaluation and personal details forms. Collaborative situations were those in which both user and system could contribute knowledge to the problem solving process. A KBS used in this way corresponds to an "expert support system", as described by Luconi, Malone and Scott Morton (1986). The analysis of problem solving behaviour in the current study was confined to the two groups who had explanations available.

Table 1 Descriptive statistics for the participants in the first study

\begin{tabular}{|c|c|c|c|c|c|c|}
\hline Variable & Min & $\operatorname{Max}$ & Mean & S.D. & Skewness & Kurtosis \\
\hline Age group ${ }^{1}$ & 2 & 7 & 4.92 & 1.28 & -0.57 & -0.14 \\
\hline Computer experience $^{2}$ & 1 & 7 & 3.54 & 2.47 & 0.29 & -1.55 \\
\hline Experience with a mouse ${ }^{2}$ & 1 & 7 & 3.58 & 2.61 & 0.30 & -1.73 \\
\hline Financial planning experience ${ }^{2}$ & 1 & 7 & 3.21 & 2.00 & 0.51 & -1.00 \\
\hline
\end{tabular}


The laboratory sessions included:

- an address by a financial planner, taking about 50 minutes;

- a 15-minute practice session using a mouse and Windows;

- familiarisation activities followed by problem solving activities with RAP for one hour, or longer if the participants wished. Feedback forms were filled out after the problems were attempted.

Data gathered from the feedback forms included age group (AGE), prior experience with computers (COMPEXP), confidence in the program (CONFID), satisfaction with the program (SATIS), and prior experience with financial planning (FINEXP). In the questionnaire used to assess users' attitudes to the expert systems, the items relating to overall satisfaction were based on the Questionnaire for User Interface Satisfaction (Chin, Diehl, and Norman, 1988). A trace of program use was captured unobtrusively on disc while participants were using the program. Data obtained from this trace included the number of times explanations were accessed during the familiarisation activities (EXPLAINF), the number of times explanations were accessed during problem solving (EXPLAIN), and a measure of overall use of explanations and other "help" facilities (HELPTOT). Performance (PERFORM) was measured by the score for answers in the problem solving session, expressed as a percentage.

\section{RESULTS}

Table 2 shows users' confidence and satisfaction with the system. The program was wellreceived, as indicated by the measures for satisfaction and confidence. Written comments made about the program were usually positive. For example:

Very clear, understandable and easy system.

Very interesting program, very useful to put things into focus before going to talk to a professional planner.

This is likely to fulfil a long felt niche for personal use - as well as for demonstration or advisory purposes.

The program would be of great benefit to retirees, provided that the programme [is] updated in line with TAX and DSS changes.

In addition, two people returned to use the program a second time, and 14 others gave contact details and requested (without prompting) to be notified if the program became available for general use. The mean performance scores were $52 \%$ on the collaborative problems and $76 \%$ on the non-collaborative problems. These results indicate that the program can be used by "ordinary" people with some success.

Table 2 Users' confidence and satisfaction with the system

\begin{tabular}{lllllll}
\hline Variable & Min & Max & Mean & S.D. & Skewness & Kurtosis \\
\hline Confidence in the system $^{1}$ & 4 & 7 & 5.98 & 0.82 & -0.41 & -0.85 \\
Satisfaction with the system $^{1}$ & 2 & 7 & 5.66 & 0.98 & -0.78 & 1.01 \\
\hline
\end{tabular}

Note. $\mathrm{n}=91{ }^{1}$ Scale 1 (low) to 7 (high) 
For the analysis of problem solving behaviour, only those participants who had explanations available and who worked on collaborative problems were studied $(N=20)$. These cases were judged to be of most interest, as an explanation facility is considered to be a characteristic of a knowledge-based system (Firebaugh, 1988). In addition, the collaborative problems are less prescriptive, and more variation in problem solving strategies was expected. The analysis of the problem solving behaviour is concerned primarily with the preference for using "what-if" analysis, compared with use of explanations as an aid to problem solving. The analysis is exploratory at this point.

Table 3 shows the correlations between variables measured in the study. Significance is shown with $p=.10$, as well as the more usual levels of $p=.05$ and $p=.01$, as the small number of cases analysed leads to low power in statistical tests. Results should be interpreted with this limitation in mind.

Age was negatively correlated with prior experience with computers, use of explanations and other help, and satisfaction with the program. Prior experience with financial planning was positively related to use of explanations in the familiarisation activities. Use of help and explanations overall was related to improved problem solving performance. Performance and satisfaction with the program were positively related.

Table 3 Correlation matrix for participants with explanations and collaborative problems

\begin{tabular}{|c|c|c|c|c|c|c|c|c|}
\hline Variable & (I) & (2) & (3) & (4) & (5) & (6) & (7) & (8) \\
\hline (1) AGE & 1.00 & & & & & & & \\
\hline (2) COMPEXP & $-.51^{* *}$ & 1.00 & & & & & & \\
\hline (3) CONFID & -.05 & -.01 & 1.00 & & & & & \\
\hline (4) EXPLAINF & $-.47^{* * *}$ & -.03 & .01 & 1.00 & & & & \\
\hline (5) EXPLAIN & -.21 & -.04 & -.05 & $.57^{* * *}$ & 1.00 & & & \\
\hline (6) FINEXP & .01 & -.25 & -.04 & $.47^{* *}$ & -.03 & 1.00 & & \\
\hline (7) HELPTOT & $-.40^{*}$ & $.41^{*}$ & .33 & .06 & $.41^{*}$ & .18 & 1.00 & \\
\hline (8) PERFORM & -.36 & .23 & .22 & .20 & .33 & -.13 & $.39^{*}$ & 1.00 \\
\hline (9) SATIS & $-.38^{*}$ & .32 & $.43^{*}$ & .24 & .08 & .17 & .33 & $.52^{* *}$ \\
\hline
\end{tabular}

Note. $\mathrm{N}=20{ }^{*} p<.10,{ }^{* *} p<.05,{ }^{* * *} p<.01$

Patterns of problem solving behaviour were examined for one problem. This problem was the first in the problem solving session. Users were given a set of data for "Adam Smith" and asked to find out what net annual income he would receive (\$15 457). They were then asked to find a way to increase Adam's income to $\$ 16000$. A correct answer involved selecting the "Use up capital" option so that some capital was invested in an annuity. A hint for this solution could be obtained from the explanations. In addition, users could explore the problem 
space by cycling back from the solution screen to the input screens and changing different options until a satisfactory solution was obtained - a type of "what-if" analysis.

Table 4 shows the patterns of behaviour observed and the number of cases in which the pattern was observed. Table 4 also shows the minimum and maximum numbers of cycles before a correct solution was obtained or the problem was abandoned.

The quickest way to obtain the correct solution would have been to change the income required field and the "income versus capital" field immediately, in the first cycle back to the input screens, without looking at explanations or help (Pattern 4). No one solved the problem in this way. Of the 18 people who attempted the problem, only two accessed explanations as their first course of action, before cycling back to the input screens. One of these two people was the only person to solve the problem on their first attempt. Another three people accessed the explanations after one cycle back to the input screens. Thus, a preference for "what-if" analysis was shown, compared with the accessing of explanations, at least in the initial stages of problem solving.

Table 4 Patterns of problem solving behaviour with frequency of occurrence and number of cycles

Number of Cycles

\begin{tabular}{lllll} 
Pattern & $N$ & Mean & Min & Max \\
\hline $\begin{array}{l}\text { (1) Problem not attempted } \\
\begin{array}{l}\text { (2) Correct answer not obtained, no use of } \\
\quad \text { explanations or help }\end{array}\end{array}$ & 2 & - & - & - \\
$\begin{array}{l}\text { (3) Correct answer not obtained, some use of } \\
\text { explanations or help }\end{array}$ & 1 & 3 & 3 & 3 \\
$\begin{array}{l}\text { (4) Correct answer obtained, no use of explanations } \\
\text { or help }\end{array}$ & 6 & 4.16 & 2 & 7 \\
$\begin{array}{l}\text { (5) Correct answer obtained, some use of } \\
\quad \text { explanations or help }\end{array}$ & 9 & 5 & 1 & 11 \\
\hline
\end{tabular}

One case is given as an example of pattern (5). This participant was male, aged 30-39 years, had used personal computers for more than two years, and indicated that he had moderate prior experience with financial planning. The participant entered the basic data given and recorded the result, as required for the first part of the problem. He then cycled back once and changed the income required field to $\$ 16000$ and observed the result (unsatisfactory). He then cycled once more, without changing any data, but consulted the help functions after achieving the same result again. On his third cycle he changed the "income versus capital" field to "maximise capital", which still did not yield the required income. On his fourth cycle, he changed the "income versus capital" field to "use up capital", and obtained a satisfactory result. 


\section{DISCUSSION}

Results from this study suggest that a system can be developed for personal financial planning that can be used by members of the general public. Participants were able to use the system successfully in problem solving - even people who had little or no prior experience with computers.

Preliminary results indicate that people choose, at least initially, a "what-if" analysis involving few EIPs rather than an explanation supplied in text format (with more EIPs if read in full). This result is seen as congruent with the cognitive effort perspective which predicts that decision makers choose problem solving strategies that require the least effort, given that acceptable outcomes are likely.

The results of this study have implications for the methods used by public service organisations and financial institutions to disseminate information and educate their clients. A system such as RAP could empower people with some funds available for investment by allowing them to explore alternatives and learn about the options available to them in their own homes, in their own time, and at their own pace. Such systems also have potential for application as "kiosk" systems in government departments and other organisations. Further work is planned to analyse problem solving behaviour more fully and to investigate outcomes of the use of advice giving systems by non-expert individuals.

\section{ACKNOWLEDGMENTS}

The RAP program was developed with assistance from Geoff Suess and other officers of the Department of Social Security. Allan Chalmers (National Bank), Barry Schmidt (Financial Wisdom) and Dave Smith (Commonwealth Bank) also gave advice on financial planning methods. The support and advice of Ron Weber is also gratefully acknowledged.

\section{REFERENCES}

Beach, L.R. and Mitchell, T.R. (1978) A contingency model for the selection of decision strategies. Academy of Management Review, 3, 439-449.

Chin, J.P., Diehl, V.A. and Norman, K.L. (1988) Development of an instrument measuring user satisfaction of the human-computer interface. CHI'88 Conference Proceedings: Human Factors in Computing. New York: Association for Computing Machinery, 213218.

Eining, M. and Dorr, P.B. (1991) The impact of expert system usage on experiential learning in an auditing setting. Journal of Information Systems, 5(1), 1-16.

Fedorowicz, J., Oz, E. and Berger, P.D. (1992) A learning curve analysis of expert system use. Decision Sciences, 23, 797 - 818.

Firebaugh, M.W. (1988) Artificial intelligence: a knowledge-based approach. Boyd \& Fraser, Boston.

Gregor, S.D. (1991) An expert system for tax law and its educational application. Unpublished M.Ap.Sc. thesis, University of Central Queensland.

Gregor, S.D., Rigney, H.M. and Smith, J.D. (1991) The applicability of a knowledge-based system to legal education. Australian Computer Journal, 23(1), 17-21 
Gregor, S.D. and Watts, J. (1991) The use of intelligent systems in taxation practice. Proceedings of the Accounting Association of Australia and New Zealand anmual conference, 7-10 July, pp 11-16.

Gregor, S.D. (1996) Explanations from knowledge-based systems for human learning and problem solving. Unpublished $\mathrm{Ph} . \mathrm{D}$. thesis, University of Queensland.

Johnson, P. and Mead, D. (1991). Legislative knowledge base systems for public administration - some practical issues. Softlaw Corp., Canberra.

Legal Knowledge Systems (1988). “AskDAN" promotional material.

Luconi, F.L., Malone, T.W. and Scott Malone, M.S. (1986) Expert systems: the next challenge for managers. Sloan Management Review, Summer, 3-14.

Miastkowski, S. (1988) Two ways to tackle your 1987 taxes, Byte, Feb.

Microsoft. (1993) Programmer's guide Microsoft Visual Basic programming system for Windows Version 3.0, U.S.A.

Newell, A. and Simon, H.A. (1972) Human problem solving. Prentice-Hall, Englewood Cliffs.

Payne, J.W. (1976) Task complexity and contingent processing in decision making: An information search and protocol analysis. Organisational Behaviour and Human Performance, 16, 366-387.

Payne, J.W., Bettman, J.R. and Johnson, E.J. (1993) The adaptive decision maker. Cambridge University Press, Cambridge.

Stansfield, J.L. and Greenfield, N.R. (1987) PlanPower: A comprehensive financial planner. IEEE Expert, Fall, 51-60.

Todd, P. and Benbasat, I. (1991) An experimental investigation of the impact of computer based decision aids on decision making strategies. Information Systems Research, 2(2), 87115.

Ward, A. (1995) Acquisition of service product knowledge. Unpublished Ph.D. thesis, Queensland University of Technology.

Wiig, K.M. (1988) The practicality of applied artificial intelligence and knowledge technology. ICAA National Congress, Gold Coast, Australia, July.

\section{BIOGRAPHY}

Shirley Gregor is a Senior Lecturer and the Head of the Department of Information Systems at Central Queensland University. She has been at the university for eleven years, and has prior experience in the computing industry in Australia and the United Kingdom. Her research interests include knowledge-based systems, human-computer interaction, and the use of technology in education. 